\title{
SYNTHESIS, STRUCTURE AND MECHANICAL PROPERTIES OF BULK "COPPER-GRAPHENE" COMPOSITES
}

\author{
V.G. Konakov ${ }^{1,2,3}$, O.Yu. Kurapova ${ }^{1,2}$, E.N. Solovyeva ${ }^{1,3}$, I.V. Lomakin ${ }^{2}$ \\ and I.Yu. Archakov ${ }^{1,4}$ \\ ${ }^{1}$ Peter the Great St. Petersburg Polytechnic University, St. Petersburg 195251, Russia \\ ${ }^{2}$ St. Petersburg State University, Universitetskaya emb. 7/9, St. Petersburg, 199034, Russia \\ ${ }^{3}$ Glass and Ceramics Ltd., 9 Linia V.O., 20, St. Petersburg, 199004, Russia \\ ${ }^{4}$ Institute for Problems of Mechanical Engineering, Russian Academy of Sciences, St. Petersburg, \\ 199178, Russia
}

Received: May 6, 2018

\begin{abstract}
Bulk copper, copper-graphene and copper-graphite composites were produced from copper-thermally expanded graphite (TEG) powder mixtures with 0-3 wt.\% TEG contents via modified powder metallurgy process that includes powder milling in a planetary mill at $350 \mathrm{rpm}$ for 5 hours, compaction, and vacuum annealing at $1030{ }^{\circ} \mathrm{C}$ for 1 hour. Phase composition and microstructure of the composites were analysed by XRD and SEM techniques. According to Raman spectroscopy, TEG transforms into a few layer graphene flakes in case of composites with $0.1-1$ wt. $\%$ of carbon additive, while for $3 \mathrm{wt} . \%$ of carbon additive it remains in the form of graphite. The addition of $0.1 \mathrm{wt} . \%$ TEG results in the tensile strength increase up to $160 \mathrm{MPa}$ (from $93 \mathrm{MPa}$ for pure copper specimen synthesized via the similar synthesis route). Vickers hardness obtained for Specimens under the study is independent from the composite composition.
\end{abstract}

\section{INTRODUCTION}

Since Chalcolithic period and Bronze age, copper $\mathrm{Cu}$ ) remains one of the most important metallic materials. It is due to its high plasticity, electrical, and thermal conductivities, as well as low expansion coefficient. Materials of copper and its alloys are widely used as the electrical contacts in electronics, machinery, civil engineering, automobiles industry, etc. [1-3]. However, certain challenges still remain in the field of copper materials application due to the low hardness and intensive copper oxidation at the elevated temperatures. The development of graphene-reinforced metal matrix composites opened a bright prospective for the novel structural applications of copper-based materials. Indeed, the extraordinary reinforcement of copper matrix is observed for both bulk copper-graphene composites and composite foils [4-7].

Graphene $(\mathrm{Gr})$ is a 2D material that is characterized by electrical conductivity close to pure copper [8-11]. Besides, Gr possesses superior mechanical properties. Its hardness is $\sim 110-120 \mathrm{GPa}$, tensile strength $\sim 125 \mathrm{GPa}$, Young's modulus is about $1100 \mathrm{GPa}$ [12]. These characteristics makes $\mathrm{Gr}$ a very promising reinforcement additive for copper matrix. It should be noted that the data on conductivity and mechanical properties listed corresponds to single layer graphene. Practically, various graphene derivatives with different layers thickness, structure, and deficiency can be introduced into copper matrix $[4,13-16]$. In the recent years, impressive variety of approaches has been developed

Corresponding author: O.Yu. Kurapova, e-mail: o.y.kurapova@spbu.ru 
for the synthesis of copper-graphene (Cu-Gr) composites. In case of bulk copper-graphene composites, powder metallurgy, microwave sintering, hotpressing, spark plasma sintering, cold pressing, hotisostatic pressing, etc. should be mentioned. The properties of $\mathrm{Cu}-\mathrm{Gr}$ composites highly depend on their manufacturing method, concentration, form and microstructure of the graphene derivative chosen as a dopant. Each method has its advantages and limitations depending on the target application of composite material. General problems of coppergraphene composites should be mentioned, they are: the difficulty of homogeneous graphene distribution in a metallic matrix, very low bonding between $\mathrm{Gr}$ and most metallic matrices, including copper, and the problem of full densification for bulk copper matrix composites. The properties of $\mathrm{Cu}-\mathrm{Gr}$ materials are usually regarded with respect to their manufacturing method, type, and concentration of graphene additive content. Powder metallurgy (PM) technique is a common approach, providing rather simple pathway for bulk metal-matrix composites (MMc) production and copper-based composites as well [1]. High energy milling and milling in a planetary mill can be regarded as the most efficient variation of PM technique. Homogeneity of graphene additive in a mixture is reached by the optimization of the treatment conditions, in case of ball milling, they are: milling time, milling rate (rpm), number of reversed cycles.

At the same time, the current data on mechanical, thermal, and electrical properties of composites is rather random $[4,16]$. According to the existing literature, the maxima of mechanical properties, electrical and heat conductivities significantly depend on graphene content and the type of graphene derivative $[1,4,13,16-18]$. So, the goal of the present work is the investigation of the effect of microstructure on the mechanical properties of bulk coppergraphene composites obtained by modified PM technique.

\section{EXPERIMENTAL}

\subsection{Composites manufacturing}

Commercial copper powder and commercial thermally expanded graphite (TEG) were used as start- ing materials in order to obtain copper-graphene composites with $0.1-3 \mathrm{wt}$.\% of carbon phase additive. Powders were mixed in the defined proportions. Then the composite specimens were fabricated by modified powder metallurgy technique recently reported by authors in [17]. The mixtures were milled in a planetary ball mill (Pulverisette 6, Fritzch) at $350 \mathrm{rpm}$ for 5 hours, another result of this milling was the mechanical activation of the powder particles. The powders subjected to the ball milling were cold pressed into pellets of $30 \mathrm{~mm}$ in the diameter and $15 \mathrm{~mm}$ in height under the pressure of 17 tons/ $\mathrm{cm}^{2}$ at room temperature without binding agents. Specimens were annealed at $1030^{\circ} \mathrm{C}$ for 1 hour in a vacuum furnace with the residual pressure less than $0.003 \mathrm{~atm}$. As a result, five sets of pellet-shaped Specimens were fabricated from the powder mixtures with various TEG additive contents, see Table 1.

\subsection{Analysis}

Thermal behavior of the Specimens was revealed via TG analysis (derivatograph MOM-3, Hungary). Samples were heated in air with the heating rate of $10^{\circ} \mathrm{C} / \mathrm{min}$. Phase composition of Specimens was determined via X-Ray diffraction analysis (XRD, Shimadzu XRD-6000). XRD measurements were carried out in air at room temperature using $\mathrm{Cu} \mathrm{K} \alpha$ radiation, $\lambda=1.54 \AA$. Microstructure of sample surface after the synthesis was investigated by scanning electron microscopy (SEM, Hitachi S-3400N with the equipment for energy dispersive analysis, EDX). Identification of the carbon derivative was performed via Raman spectroscopy technique (Senterra, Bruker, wavelength $488 \mathrm{~cm}^{-1}$ ). The particle size distribution in the powders was measured by the particle size distribution analysis (PSD, Horiba LA-950). Vickers hardness (HV) was determined at the load of $0.5 \mathrm{~kg}$ applied for 15 seconds (Shimadzu HMV-G21, diamond pyramid shaped indenter), the data for each Specimen were averaged over 20 tests. The samples with the size of $1 \times 2 \times 6 \mathrm{~mm}$ underwent mechanical tension tests with the deformation rate of $10^{-3} \mathrm{sec}^{-1}$ (Shimadzu AG-X Plus), the data were averaged over three tests. Following parameters were investigated: $\sigma_{y}-$ yield limit, UTS -Ultimate Tensile Stress.

Table 1. Composition and numeration of the Specimens.

\begin{tabular}{llllll}
\hline Specimen number & $\begin{array}{l}1 \text { (Reference sample } \\
\text { - pure Cu) }\end{array}$ & 2 & 3 & 4 & 5 \\
\hline $\begin{array}{l}\text { TEG contents in the initial } \\
\text { powder mixture, wt.\% }\end{array}$ & 0 & 0.1 & 0.5 & 1 & 3 \\
\hline
\end{tabular}




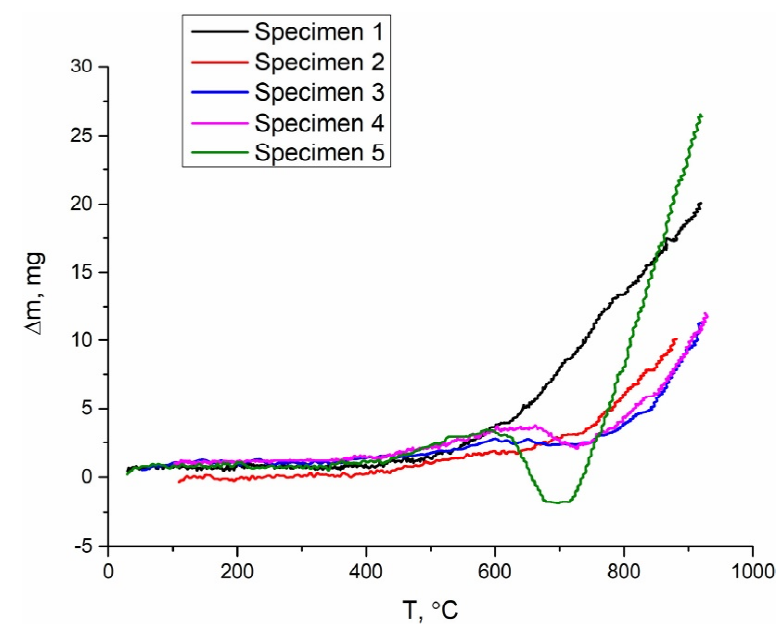

Fig. 1. TG data obtained for Specimens $1-5$ in air.

\section{RESULTS AND DISCUSSION}

The results of TG analysis performed in air for Specimens 1-5 are shown in Fig. 1. As it is seen from TG curves, oxidation resistance for Specimen 1 (pure copper) and composite Specimens 2-5 differs significantly. In general, Cu-Gr composites (Specimens 2-4) are more resistant to the oxidation comparing to pure copper material (Specimen 1). For instance, the oxidation of Specimen 1 begins at $~ 500^{\circ} \mathrm{C}$, while for $\mathrm{Cu}-\mathrm{Gr}$ composites that temperature shifts to $\sim 600-750^{\circ} \mathrm{C}$. The significant mass losses are observed in the TG curves of Specimens 4 and 5 at $\sim 670-730^{\circ} \mathrm{C}$; this effect is most probably due to the carbon additive burning out during the heating in air. Indeed, the estimated mass losses here correspond to the initial amount of TEG added, i.e. 1 and 3 wt.\%. It is worth to mention that the mass gain of Specimen 5 is more intensive than those in case of Specimen 1. It is likely due to the additional heat elaborated during carbon additive burn out.

As an example, XRD patterns of Specimens 1 and 5 after the annealing in vacuum are presented in Fig. 2. As seen from Fig. 2a, the phase composition of Specimen 1 (peaks at $2 \theta=43,50.5$, and $74^{\circ}$ ) corresponds to pure copper with no admixture of copper oxide. Rather wide peaks indicate that the structure of the sample is not well formed. It should be noted that similar XRD patterns were obtained for the composite Specimens 2-4 with 0.1-1 wt.\% of TEG in the initial powder mixture. Peaks at $2 \theta=26.5$ and $36.5^{\circ}$ attributed to carbon additives become visible at high TEG content of 3 wt.\% (see Fig. 2b). Peak intensities in XRD patterns of all the Specimens are comparable, indicating that the crystallinity degree of the samples is similar.

The indication of the carbon additive was carried out using Raman spectroscopy technique. In case of Specimens 1-3, the fluorescence effect of copper matrix was rather high; hence, the bands corresponding to the carbon additive were seen very slightly. Raman spectra obtained for composite Specimens 4 and 5 are presented in Fig. 3. Let us discuss them in more detail. As seen from Fig. $3 a$ demonstrating the spectrum of Specimen 4 ( $1 \mathrm{wt} . \%$ of TEG in the initial powder mixture), the bands at 1362,1592 , and $2720 \mathrm{~cm}^{-1}$ are registered here in addition to copper fluorescent bands. Their position corresponds to $\mathrm{D}, \mathrm{G}$, and 2D bands for graphene, see the discussion in [4] for more details. Since D and $G$ bands are overlapping and their intensities are comparable, it can be concluded that the graphene here exists in a form of few layered flakes. Note that the position of the discussed bands is the same in the spectra registered for Specimens 2 and 3 (not shown in Fig. 3), so, one can suggest that TEG in these composites with relatively low carbon additive contents also transforms to graphene fewlayered flakes. Upon the increase of TEG content, bands position shifts to the right manifesting that the carbon additive here is generally in the form of graphite rather than graphene [4]. The presence of
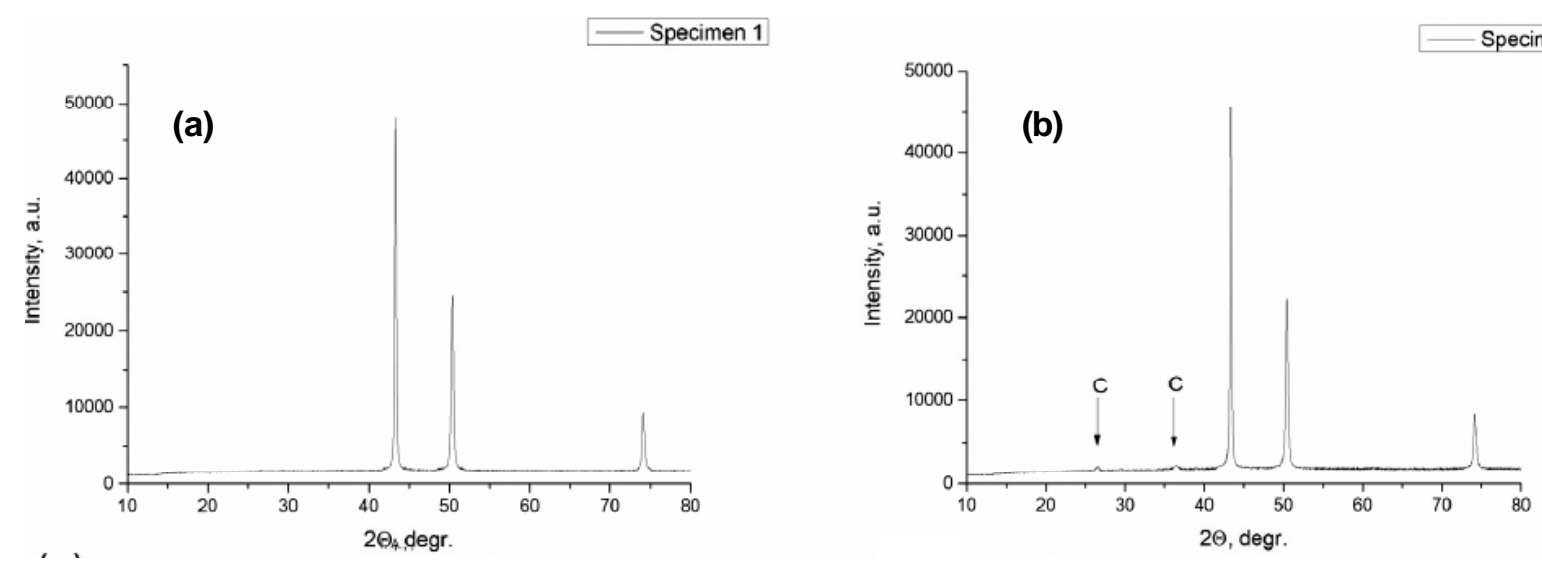

Fig. 2. XRD patterns of (a) Specimen 1 and (b) Specimen 5 after synthesis. 

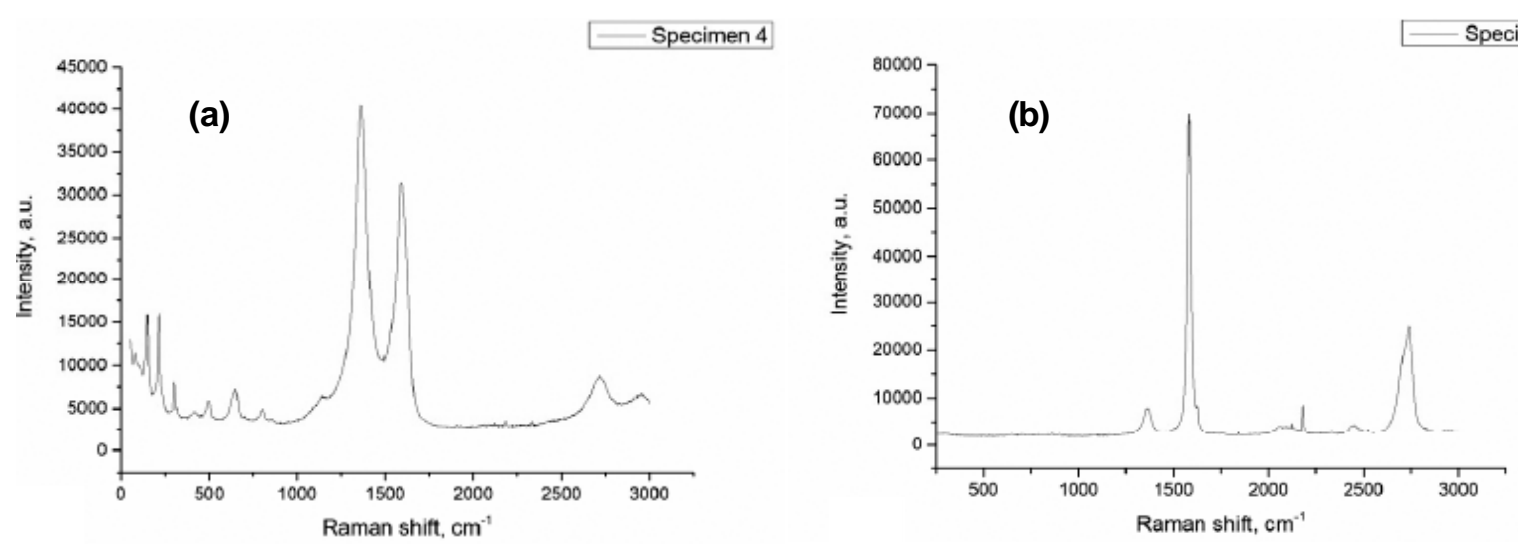

Fig. 3. Raman spectra obtained for composite Specimens (a) 4 and (b) 5.
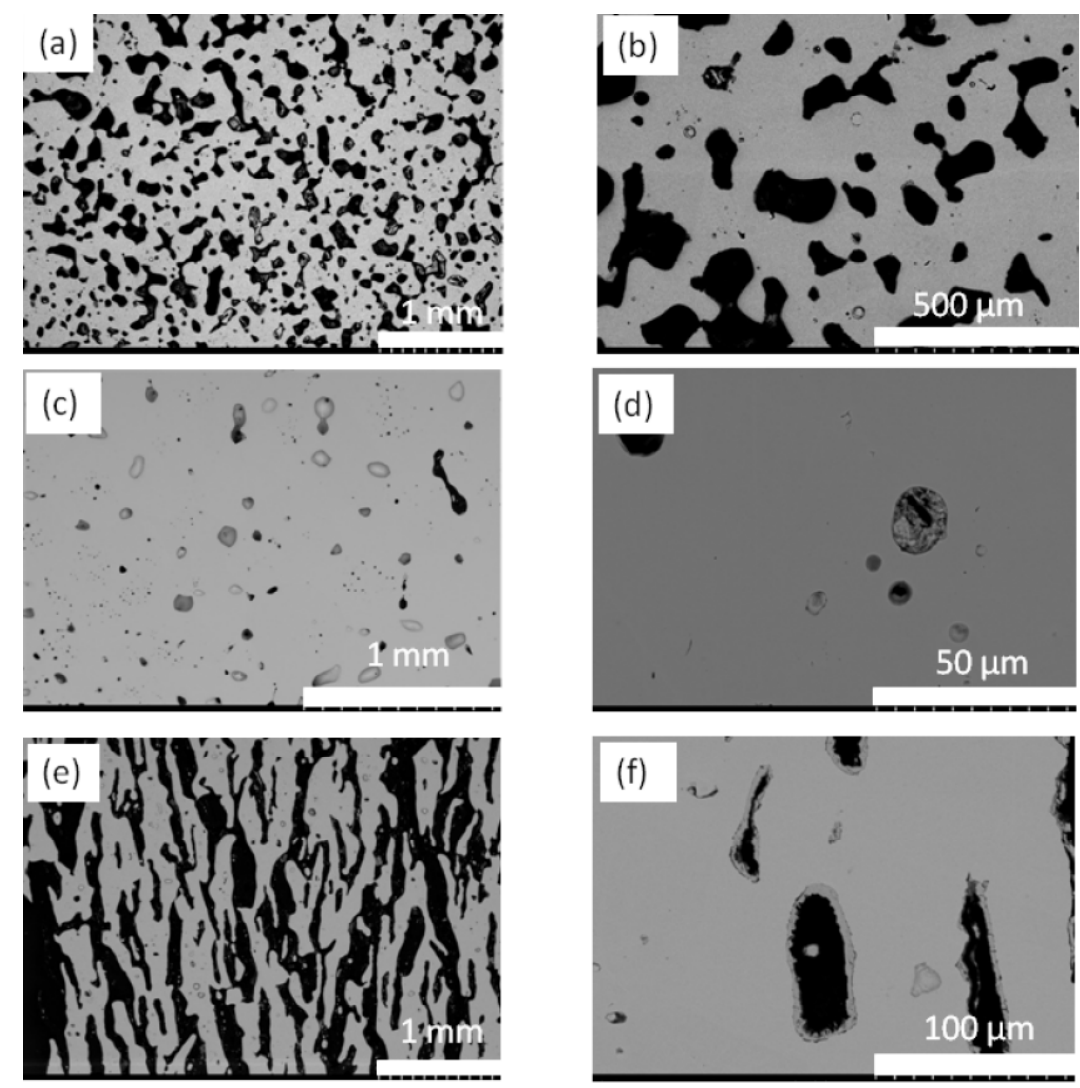

Fig. 4. SEM data of the polished surface of the reference sample - pure copper, Specimen 1: (a) magnitude $\times 1$ and (b) magnitude $\times 10$; composite with $0.1 \mathrm{wt} . \%$ of carbon addition, Specimen 2: (c) magnitude $\times 1$ and (d) magnitude $\times 100$; composite with 3.0 wt.\% of carbon addition, Specimen 5: (e) magnitude $\times 1$ and (f) magnitude $\times 10$.

the additional small peaks is likely due to the chaotic packing of graphite plates in the sample.

The microstructure of the Specimens is presented in Fig. 4. From SEM data shown in Figs. $4 \mathrm{a}$ and $4 \mathrm{~b}$, one can conclude that Specimen 1 (reference sample, pure bulk copper) is rather porous. The pores are large and have an irregular shape. Several pores aggregations can be also distinguished. It is probably due to wide particle size distribution in the copper powder after the ball milling, see the particle size distribution in the copper powder before and after milling in a planetary shown in Fig. 5 .

As it is seen from Fig. 5, the particle size distribution after the milling is narrower than for the initial copper powder, it can be also concluded that the fraction of large particles with the typical linear dimensions $>40 \mu \mathrm{m}$ is absent in the milled powder. Despite copper is rather ductile, milling results in $\sim 2$ times mean particle size decrease from 14.77 to $8.35 \mu \mathrm{m}$ proving that the rate of $350 \mathrm{rpm}$ is enough 


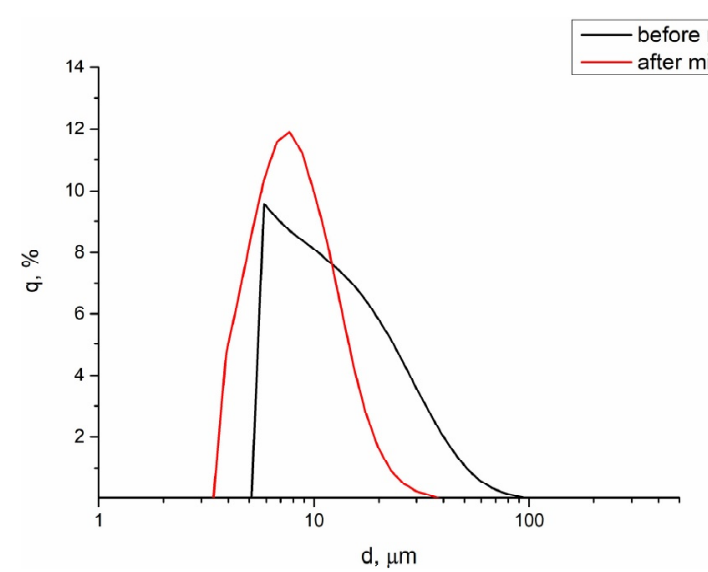

Fig. 5. Particle size distribution in copper powders before and after milling.

for the effective milling, in addition, it demonstrates that the agglomeration of copper particles was avoided during the milling process. It should be mentioned that much higher milling rates (1400$1700 \mathrm{rpm})$ were reported in $[18,19]$ as optimal milling conditions.

The addition of 0.1 wt. $\%$ of TEG, see Figs. 4c and $4 \mathrm{~d}$, results in significant decrease in the material porosity: the pores amount decreases and the pore shape changes to spherical. It can be considered that the carbon additive here, most likely, acts as a lubricant simplifying composite powder compaction. That leads to bulk composite material formation with the residual porosity. This fact agrees with the data reported in [20]; the authors used the similar synthesis approach (ball milling and coldpressing compaction) and obtained copper-graphene composites with a low porosity level of $10-12 \%$. The increase in TEG contents, see Figs. $4 \mathrm{e}$ and $4 \mathrm{f}$ for Cu-Gr composite with 3 wt.\% TEG contents, results in Specimen porosity increase, pores elongation, and microstructure transformation to a lamellar one. Microstructure changes observed here are in the agreement with the Raman data discussed above, see Fig. 3. Based on the data obtained, it can be suggested that carbon additive is not distributed homogeneously in the copper matrix in case of the maximal carbon addition contents. The excess of carbon additive is likely extruded to the pores and other microstructural defects, rather than stays at the grain boundaries. Thus, elongated pores are formed during the annealing.

Fig. 6 shows the data on Vickers hardness of the composites fabricated from the powder mixtures with various TEG content. Note that the mechanical tests were not performed for Specimen 5 with the maximal TEG contents of 3 wt.\% of TEG be-

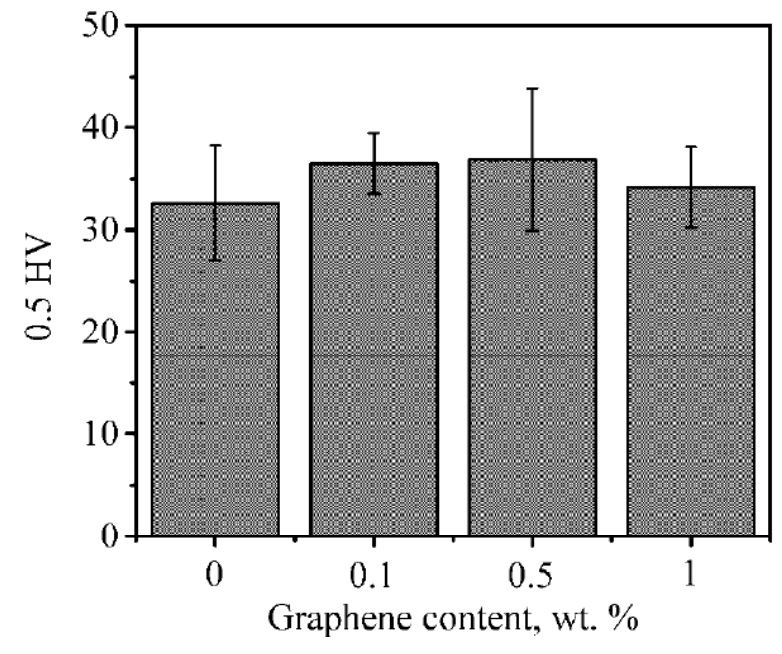

Fig. 6. The effect of TEG contents in the initial powder mixture on composite microhardness.

cause of the severe porosity porosity of the sample. Analyzing the figure, one can see that carbon additive does not affect the material microhardness within the experimental error. It should be noted that Specimen 2 with 0.1 wt.\% of TEG in the initial powder mixture is characterized by the minimal error scatter. It can be concluded that that graphene in these Specimens is present in pores and other microstructure defects rather than on grain boundaries or in the copper matrix. So the microhardness measurement took place all the time in the same material, i.e. in the copper matrix.

Stress-strain diagrams obtained for Specimens 1-4 fabricated from the powder mixtures with various TEG content are shown in Fig. 7. Comparison of the typical stress-strain diagrams for pure copper Specimen 1 and composite Specimens 2-4 gives evidence to different mechanical behavior of these

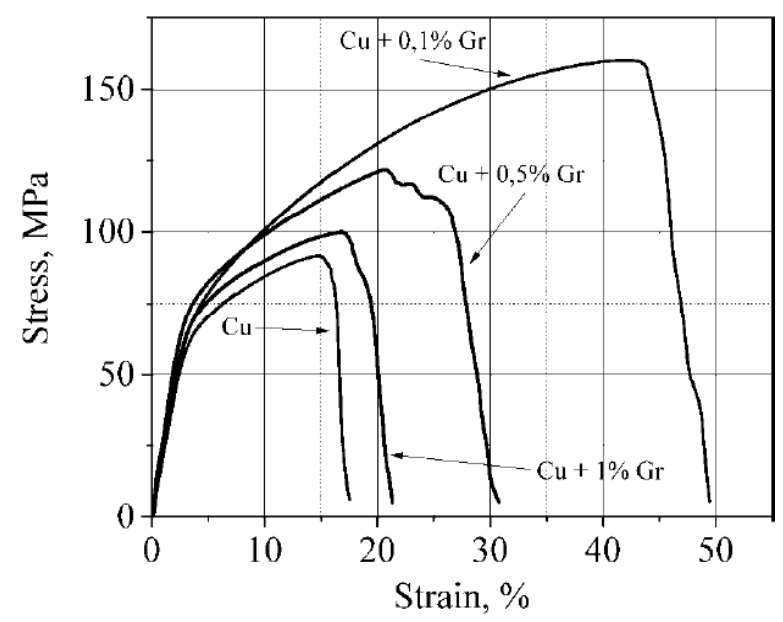

Fig. 7. Stress-strain diagrams obtained for Specimens 1-4. 


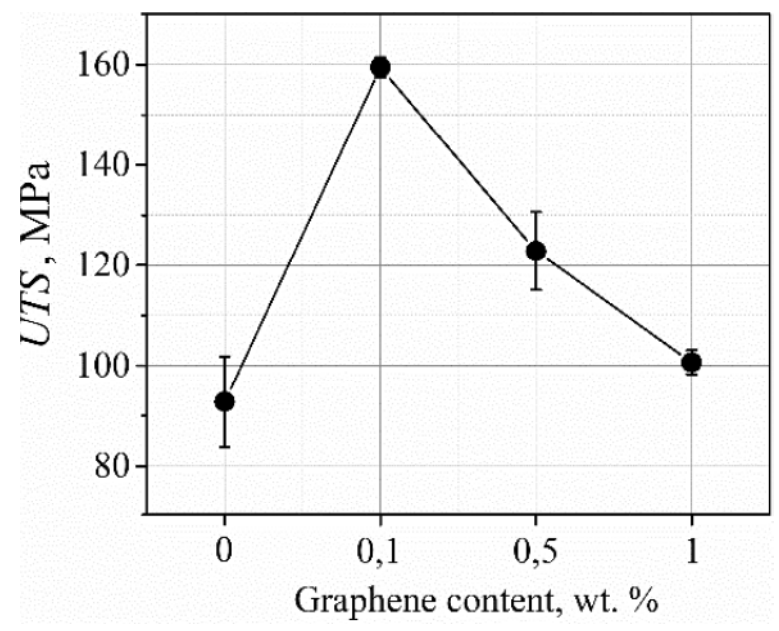

Fig. 8. The effect of TEG addition in the initial powder mixture on ultimate tensile strength obtained for Specimens 1-4.

materials. The TEG addition significantly affects plastic deformation and strain hardening. Further analysis of the mechanical parameters change shows that yield stress value $\left(\sigma_{y}\right)$ does not change upon TEG contents increase. In contrast to yield stress and microhardness, the values of ultimate tensile strength change nonlinearly (see Fig. 8).

The addition of $0.1 \mathrm{wt}$ \% TEG results in the significant tensile strength increase from $93 \mathrm{MPa}$ for cure copper to $160 \mathrm{MPa}$ for composite Specimen 2. Further TEG contents increase up to $1 \mathrm{wt} . \%$ leads to UTS value decrease to $100 \mathrm{MPa}$ (see Fig. 8). At the same time, the value obtained for any of composite Specimens is higher than for that of pure copper. In analogy with conventional copper alloys, a small TEG addition likely acts like a barrier that creates the dislocation loops around the structural defects during the deformation. Latter results in the increase of the hardening step. This hypothesis is in the agreement with SEM and XRD data obtained for the studied Specimens.

\section{CONCLUSONS}

Using SEM technique, it was shown that the addition of TEG powder induces microstructure transformation from bulk porous in case of pure copper to practically non-porous for "CU- $0.1 \mathrm{wt}$. $\%$ TEG" composite and lamellar for "Cu-3wt.\%TEG" composite. By means of Raman spectroscopy, it was proved that thermally expanded graphite during the synthesis transforms into graphene flakes when the TEG amount in the initial powder mixture is $0.1-1$ wt. $\%$ and remains graphite at $3 \mathrm{wt} . \%$ of TEG contents. The maximum of ultimate tensile strength was observed for "Cu-0.1wt.\%TEG" composite being 1.8 times higher than for pure copper specimen. Using XRD, SEM, Vickers hardness, and mechanical testing data, it was shown that carbon phase (graphene for samples with $0.1-1 \mathrm{wt} . \%$ TEG contents in the initial mixture) is not present on grain boundaries but is allocated in microstructure defects.

\section{ACKNOWLEDGEMENTS}

This research work was supported by Ministry of Education and Science of Russian Federation. Zadanie \#16.3483.2017/PCh. SEM data was obtained at the Research park of St.Petersburg State University Center for Geo-Environmental Research and Modeling (GEOMODEL)». Raman spectroscopy analysis was performed at the Center for Optical and Laser Materials Research of St. Petersburg State University. Mechanical testing was supported by Saint Petersburg State University via Lot 2017, applied (Id: 26130576).

\section{REFERENCES}

[1] W. Li, D. Li, Q. Fu and C. Pan // RSC Advances 98 (2015) 80428.

[2] I. A. Ibrahim, F. A. Mohamed and E. J. Lavernia // Journal of materials science 26 (1991) 1137.

[3] Y. Lee, J. R. Choi, K. J. Lee, N. E., Stott and D. Kim // Nanotechnology 41 (2008) 415604.

[4] Vladimir G. Konakov, Ivan Yu. Archakov and O. Yu. Kurapova, In: Handbook of Graphene: Volume 4, ed. by Cengiz Ozkan (Wiley, 2019), p. 283 (in print).

[5] S. Stankovich, D. A. Dikin, G. H. B. Dommett, K. M. Kohlhaas, E. J. Zimney, E. A. Stach, R. D. Piner, S. T. Nguyen and R. S. Ruoff // Nature 442 (2006) 282.

[6] S. M. Uddin, T. Mahmud and C. Wolf // Composites Science and Technology 70 (2010) 2253.

[7] L. Zhang Z. Duan, H. Zhu and K. Yin // Materials and Manufacturing Processes 32 (2017) 475.

[8] A. K. Geim and K. S. Novoselov // Nature materials 6 (2007) 183.

[9] M. D. Stoller, S. Park, Y. Zhu, J. An and R. S. Ruoff // Nano letters 10 (2008) 3498.

[10] A. A. Balandin, S. Ghosh, W. Bao, I. Calizo, D. Teweldebrhan, F. Miao, and C. N. Lau // Nano letters 3 (2008) 902.

[11] S. W. Chang, A. K. Nair and M. J. Buehler // Journal of Physics: Condensed Matter 24 (2012) 245301. 
[12] C. Lee, X. Wei, J. W. Kysar and J. Hone // Science 321 (2008) 385.

[13] J. Dutkiewicz, P. Ozga, W. Maziarz, J. Pstruś, B. Kania, P. Bobrowski and J. Stolarska // Materials Science and Engineering: A 628 (2015) 124.

[14] Y. Kim, J. Lee, M. S. Yeom, J. W. Shin, H. Kim, Y. Cui and S. M. Han // Nature communications 4 (2013). DOI: ncomms3114.

[15] D. Zhang and Z. Zhan // Journal of Alloys and Compounds 654 (2016) 226.
[16] X. Wang, J. Li, and Y. Wang // Materials Letters 181 (2016) 309.

[17] O. Yu. Kurapova, I. V. Lomakin, E. N. Solovieva, I. Yu. Archakov and V. G. Konakov // Rev. Adv. Mater. Sci. 52 (2017) 99.

[18] K. Chu and C. Jia // Physica status solidi (a) 211 (2014) 184.

[19] L. Wang, H. Choi, J. M. Myoung and W. Lee // Carbon 47 (2009) 3427.

[20] S. Manjunath, L. H. Manjunatha and V. Kumar // International Journal of Advances in Scientific Research and Engineering 3 (2017) 147. 